\section{SAT0635 MAGNETIC RESONANCE IMAGING OF THE CERVICAL SPINE IN PATIENTS WITH RHEUMATOID ARTHRITIS AND ANKYLOSING SPONDYLITIS PRESENTING WITH CHRONIC NECK PAIN - A SYSTEMATIC COMPARISON OF CLINICAL ASSESSMENTS}

X. Baraliakos, M. Soltani, U. Kiltz, J. Braun. Rheumazentrum Ruhrgebiet, Herne, Germany

Background: Despite the differences in pathogenesis, neck pain associated with functional limitation and impaired mobility of the cervical spine is a frequent clinical symptom of patients with rheumatoid arthritis (RA) and ankylosing spondylitis (AS)

Objectives: To directly compare inflammatory and structural findings obtained by magnetic resonance imaging (MRI) in patients with RA and AS who present with chronic neck pain, and to correlate MRI findings with clinical measurements.

Methods: A total of 120 patients (60 RA and $60 \mathrm{AS}$ ) were consecutively included in the study if they had chronic neck pain (duration $>3$ months). All patients had clinical examinations for neck function and mobility and were asked to fill in disease specific questionnaires. They also had laboratory examinations (CRP, ESR) and MRI of the cervical spine (CS) using contrast-enhanced MRI sequences (T1 pre- and post-Gadolinium, sagittal and axial images). A total of 107 patients (59 RA with 295 and 48 AS with 240 vertebral segments) could be finally evaluated. An experienced rheumatologist examined all patients blinded to diagnosis and MR images. In addition, two experienced readers blinded to patients' diagnosis and clinical assessments evaluated the MRIs by describing the anatomical structures of the CS (vertebral body, intervertebral disc, facet joints) and the pattern of inflammatory activity in the bone marrow (vertebral edges vs. vertebral endplates)

Results: The RA group included more females (66.1\%) and older patients (58.6 \pm 11.4 years) in comparison to AS (68.8\% males, mean age $47.9 \pm 13.1$ years), while there were no differences in the duration of neck pain. AS patients reported higher mean levels of neck pain on a $0-10$ numerical rating scale $(5.0 \pm 3.6)$ as compared to RA patients $(3.0 \pm 3,1)(p=0.003)$, while the Northwick pain questionnaire didn't reveal any differences. There were numerically more patients with AS $(n=11,22.9 \%)$ than $R A(n=9,15.3 \%)(p=0.166)$ with bone marrow oedema (BME) at the vertebral edges. The majority of lesions was located in the lower $\mathrm{CS}$. In contrast, more patients with RA $(n=18,30.5 \%)$ than AS $(n=3,6.3 \%)$ had erosive osteochondrosis with endplate BME $(p=0.002)$. Atlantoaxial synovitis was found in only 1 patient with RA $(1.7 \%)$, while inflammatory changes around the dens axis were found in $2(3.4 \%)$ and atlantodental synovitis in $5(8.5 \%)$ RA patients but not in AS patients. In comparison, erosive changes in the dens axis region were found in 3 RA $(5.1 \%)$ vs. 2 AS $(4.1 \%)$ patients. No major differences related to the presence of facet joint osteoarthritis was found ( $78 \%$ in RA vs. $65 \%$ in AS). The prevalence of facet joint osteoarthritis was the only imaging finding correlating with clinical symptoms: $r=0.259(p=0.049)$ for $R A$ and $r=0.416(p=0.003)$ for AS, respectively. Similarly, only facet joint osteoarthritis correlated with restriction of cervical rotation in patients with $\mathrm{AS}(\mathrm{r}=0.471, \mathrm{p}=0.001)$.

Conclusions: Both BME and chronic changes of the lower part of the CS but not of the atlantoaxial region are seen in patients with RA and AS who present with chronic neck pain. The pattern of BME involvement in patients with RA vs. AS was different. Facet joint osteoarthritis was the only imaging finding that correlated with the magnitude of neck pain, in AS it also correlated with impaired cervical rotation. Disclosure of Interest: None declared

DOI: 10.1136/annrheumdis-2018-eular.7570

\section{SAT0636 REPEATABILITY OF MRI DIFFUSION WEIGHTED IMAGINGOF SACROILIAC JOINTS IN PATIENTS WITH AXIAL SPONDYLOARTHRITIS AND HEALTHY SUBJECTS}

J.M. Møller ${ }^{1}$, M. Østergaard ${ }^{2}$, H.S. Thomsen ${ }^{1}$, I.J. Sørensen², O.R. Madsen², S. J. Pedersen ${ }^{2} .{ }^{1}$ Radiology, Herlev Hospital, Herlev, ${ }^{2}$ COPECARE, Center for Rheumatology and Spine Diseases, Rigshospitalet, Copenhagen, Denmark

Background: Bone marrow oedema (BME) localised in sacroiliac joints (SIJ) as assessed by Short Tau Inversion Recovery (STIR) or T2 weighted fat saturated (T2w FS) sequences is one of the two cornerstones in the classification criterion for axial spondyloarthritis (SpA). Since Diffusion Weighted Imaging (DWI) can quantify water diffusion by measuring the Apparent Diffusion Coefficient (ADC), DWI may potentially be an alternative or supplementary imaging method to STIR or T2w FS. ${ }^{1}$

Objectives: The purpose was to measure the repeatability of (ADC) in a standardised Region-of-Interest (ROI) setting in healthy subjects and in active and chronic SpA patients and to compare the subjects.

Methods: SpA patients and sex- and age- matched healthy subjects were examined twice within $7 \pm 2$ days in the same MRI unit. Short Tau Inversion Recovery (STIR), T1 weighted and DWI sequences were performed in the semi-coronal plane. ADC map was calculated on basis of $4 \mathrm{~b}$ values: $0 ; 50 ; 500 ; 800$. On each consecutive slice in the cartilaginous compartment the SIJ was divided into four quadrants. From the joint surface a $5 \mathrm{~mm}$ deep ROI was drawn. In all ROls median and 95th percentile ADC values were measured. Intraclass Correlation Coefficients (ICC) were measured to assess repeatability, and unpaired $T$ tests to compare subgroups. Actives were defined as BME on STIR and non-actives as no BME on STIR.

Results: $25 \mathrm{SpA}$ patients and 24 healthy subjects were enrolled. For all subjects inter-reader ICC was 0.66 and intra-reader ICC 0.92 for the median ADC and 0.57 and 0.74 for the 95th percentile ADC. In SpA patients, healthy subjects, females, males, actives and non-actives Inter-reader ICC was $0.79,0.27,0.42,0.72,0.78$ and 0.52 for the median ADC and $0.74 ; 0.73,0.68,0.60,0.88,0.64$, and 0.64 for the 95th percentile. Intrareader ICC was excellent for median ADC and good to excellent for 95th percentile ADC (table 1). Significant differences in median (figure $1 A$ ) and 95th percentile (fig 1B) $A D C$ were measured between females versus males $(p=0.03 ; p=0.02)$ and actives versus non-actives $(p=0.01 ; p=0.01)$ but not in patients versus healthy controls.

Abstract SAT0636 - Table 1. Intraclass correlation coefficient (ICC) for median ADC and 95th percentile ADC measurements in subgroups.

\begin{tabular}{|c|c|c|c|c|}
\hline & $\begin{array}{c}\text { Inter Reader ICC } \\
(95 \% \mathrm{Cl}) \\
\text { Median ADC }\end{array}$ & $\begin{array}{c}\text { Inter Reader ICC } \\
(95 \% \mathrm{Cl}) \\
\text { 95th percentile } \\
\text { ADC }\end{array}$ & $\begin{array}{c}\text { Intra Reader ICC } \\
(95 \% \mathrm{Cl}) \\
\text { Median ADC }\end{array}$ & $\begin{array}{c}\text { Intra Reader ICC } \\
(95 \% \text { Cl) } \\
\text { 95th percentile } \\
\text { ADC }\end{array}$ \\
\hline All subjects & $0.66(0.46 ; 0.80)$ & $0.57(0.33 ; 0.73)$ & $0.92(0.86 ; 0.95)$ & $0.74(0.58 ; 0.85)$ \\
\hline SpA & $0.79(0.58 ; 0.90)$ & $0.69(0.40 ; 0.85)$ & $0.92(0.82 ; 0.96)$ & $0.73(0.47 ; 0.87)$ \\
\hline Healthy & $0.27(-0.17 ; 0.61)$ & $0.13(-0.30 ; 0.51)$ & $0.95(0.88 ; 0.98)$ & $0.68(0.39 ; 0.85)$ \\
\hline Female & $0.42(0.01 ; 0.71)$ & $0.45(0.04 ; 0.73)$ & $0.87(0.72 ; 0.94)$ & $0.60(0.24 ; 0.81)$ \\
\hline Male & $0.72(0.45 ; 0.87)$ & $0.63(0.31 ; 0.82)$ & $0.93(0.86 ; 0.97)$ & $0.88(0.75 ; 0.94)$ \\
\hline $\begin{array}{l}\text { BME on } \\
\text { STIR }\end{array}$ & $0.78(0.16 ; 0.96)$ & $0.75(0.08 ; 0.95)$ & $0.92(0.59 ; 0.99)$ & $0.64(-0.12 ; 0.93)$ \\
\hline $\begin{array}{l}\text { No BME on } \\
\text { STIR }\end{array}$ & $0.52(0.24 ; 0.71)$ & $0.29(-0.03 ; 0.55)$ & $0.93(0.87 ; 0.96)$ & $0.69(0.48 ; 0.82)$ \\
\hline
\end{tabular}
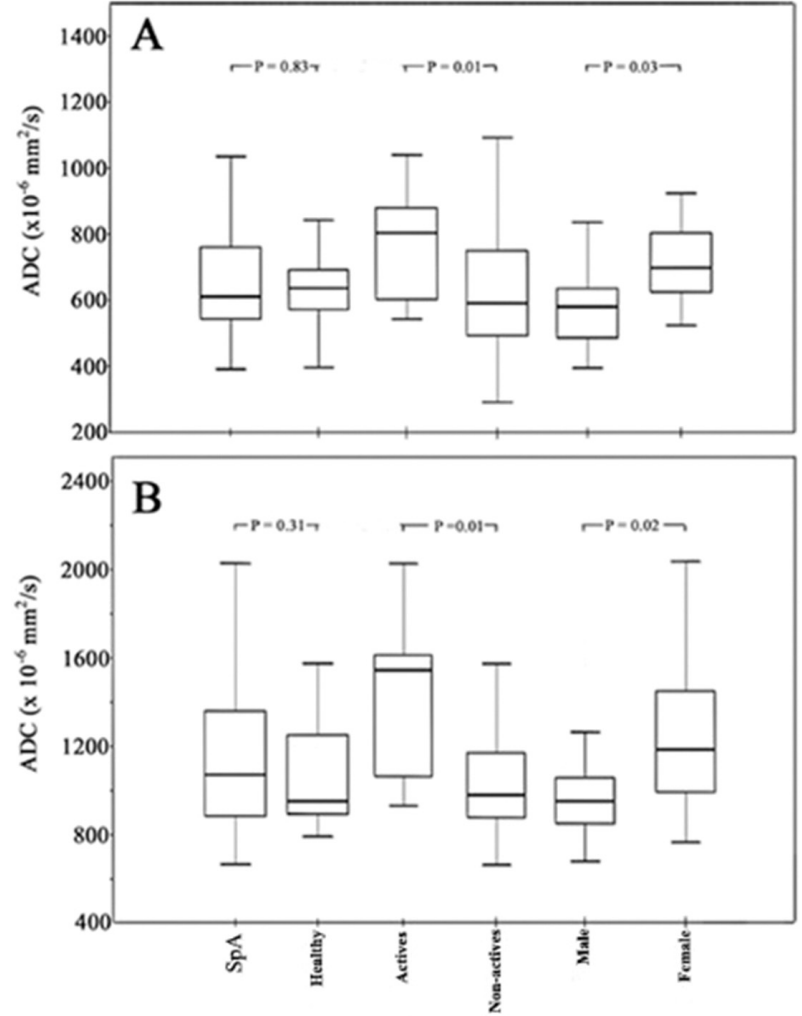

Conclusions: ADC seems a reliable parameter in SpA patients but not in healthy subjects. Our data encourage further studies of ADC measurements for discrimination of SpA patients with or without active inflammation.

\section{REFERENCE:}

[1] Navallas M, et al. Radiographics 2013;33(4):933-956.

Disclosure of Interest: None declared

DOI: 10.1136/annrheumdis-2018-eular.2503 